\title{
Consumption of a calcium and vitamin D-fortified food product does not affect iron status during initial military training: a randomised, double-blind, placebo-controlled trial
}

\author{
Stephen R. Hennigar ${ }^{1} \dagger$, Erin Gaffney-Stomberg ${ }^{2} \dagger$, Laura J. Lutz ${ }^{1}$, Sonya J. Cable ${ }^{3}$, Stefan M. Pasiakos ${ }^{1}$, \\ Andrew J. Young ${ }^{1}$ and James P. McClung ${ }^{1 *}$ \\ ${ }^{1}$ Military Nutrition Division, United States (US) Army Research Institute of Environmental Medicine, Natick, MA O1760, USA \\ ${ }^{2}$ Military Performance Division, United States (US) Army Research Institute of Environmental Medicine, Natick, MA O1760, USA \\ ${ }^{3}$ Initial Military Training Center of Excellence, Fort Eustis, VA 23604, USA
}

(Submitted 21 September 2015 - Final revision received 23 October 2015 - Accepted 28 October 2015 - First published online 2 December 2015)

\begin{abstract}
$\mathrm{Ca} /$ vitamin D supplementation maintains bone health and decreases stress fracture risk during initial military training (IMT); however, there is evidence that Ca may negatively affect the absorption of other critical micronutrients, particularly Fe. The objective of this randomised, doubleblind, placebo-controlled trial was to determine whether providing $2000 \mathrm{mg} / \mathrm{d} \mathrm{Ca}$ and $25 \mu \mathrm{g} / \mathrm{d}$ vitamin D in a fortified food product during 9 weeks of military training affects Fe status in young adults. Male ( $n$ 98) and female ( $n$ 54) volunteers enrolled in US Army basic combat training (BCT) were randomised to receive a snack bar with Ca/vitamin $\mathrm{D}(n$ 75) or placebo (snack bar without Ca/vitamin $\mathrm{D} ; n$ 77) and were instructed to consume 2 snack bars/d between meals throughout the training course. Circulating ionised Ca was higher $(P<0 \cdot 05)$ following BCT among those consuming the $\mathrm{Ca} /$ vitamin D bars compared with placebo. Fe status declined in both groups over the course of BCT. Transferrin saturation, serum ferritin and $\mathrm{Hb}$ were reduced $(P<0.05)$ and soluble transferrin receptor increased $(P<0 \cdot 05)$ following BCT. There were no differences $(P>0.05)$ in markers of Fe status between placebo and $\mathrm{Ca} /$ vitamin $\mathrm{D}$ groups. Collectively, these data indicate that $\mathrm{Ca} /$ vitamin D supplementation through the use of a fortified food product consumed between meals does not affect Fe status during IMT.
\end{abstract}

Key words: Minerals: Bioavailability: Iron deficiency: Calcium/vitamin D supplementation

Up to $2-5 \%$ of males and $8-21 \%$ of females sustain a stress fracture during initial military training $\left(\right.$ IMT) ${ }^{(1)}$, which can lead to increased rates of attrition. Recent trials have demonstrated that supplemental $\mathrm{Ca}$ and vitamin D during IMT have positive effects on bone health and reduce stress fracture risk ${ }^{(2-4)}$. For example, one study documented a decreased relative risk (up to $20 \%$ ) of fracture in female recruits supplemented with $2000 \mathrm{mg} \mathrm{Ca}$ and $20 \mu \mathrm{g}$ vitamin $\mathrm{D} / \mathrm{d}$ during navy $\mathrm{IMT}^{(2)}$. Most recently, a randomised controlled trial demonstrated that supplementation with $2000 \mathrm{mg} \mathrm{Ca}$ and $25 \mu \mathrm{g}$ vitamin $\mathrm{D} / \mathrm{d}$ during Army IMT increased circulating ionised Ca (iCa), maintained parathyroid hormone (PTH) levels, increased the circulating osteoprotegerin:receptor activator of NF- $\mathrm{BB}$ ligand (OPG:RANKL) ratio and improved several peripheral quantitative computed tomography measures of bone health ${ }^{(4)}$. Although the protective effects of supplemental $\mathrm{Ca}$ and vitamin D have been demonstrated, poor Fe status remains a threat to physical and cognitive performance during IMT, as the Fe status of male and female soldiers declines throughout the course $^{(5-8)}$. Up to approximately 33 and $21 \%$ of female soldiers develop Fe deficiency or Fe-deficient anaemia during training, and the deleterious effects of poor Fe status on physical and cognitive function during military training and operationally demanding tasks have been characterised ${ }^{(5-8)}$. Thus, interventions to prevent bone injury, while improving or maintaining $\mathrm{Fe}$ status, are important for optimising the health and performance of military trainees and for the successful completion of training and entry into the armed forces.

Despite the benefits of supplemental Ca on bone health, several studies indicate that $\mathrm{Ca}$ may interfere with Fe absorption in animals and humans ${ }^{(9,10)}$. For example, early studies in animals documented 57, 86 and $90 \%$ decreases in liver, blood and carcass Fe contents in rats fed a $\mathrm{CaCO}_{3}$-supplemented diet compared with a basal diet for 5 weeks ${ }^{(9)}$. Interestingly, the liver Fe content of the Ca-supplemented rats was lower compared with anaemic controls, suggesting that the addition of Ca to the diet may have detrimental effects on Fe status. In humans, single meal studies with added Ca documented approximately $30-80 \%$ reductions in non-haeme and haeme Fe absorption ${ }^{(11-14)}$, although, longerterm, longitudinal studies ${ }^{(15,16)}$ and studies where Ca was given

Abbreviations: BCT, basic combat training; DMT1, divalent metal transporter 1; IMT, initial military training.

* Corresponding author: J. P. McClung, fax +1 508233 4869, email james.p.mcclung8.civ@mail.mil

$\dagger$ These authors contributed equally to this work. 
separate from meals ${ }^{(17)}$ have not reported an effect on $\mathrm{Fe}$ absorption or status. Further, the effects of providing supplemental $\mathrm{Ca}$ and vitamin $\mathrm{D}$ in a fortified food product on Fe status have not been explored in a military population during physical training. As such, the objective of the present study was to determine whether providing $2000 \mathrm{mg} / \mathrm{d} \mathrm{Ca}$ in a fortified food product during 9 weeks of military training affects Fe status in young adults. We hypothesised that supplemental $\mathrm{Ca}$ as a fortified food product would further exacerbate declines in Fe status during IMT.

\section{Methods \\ Volunteers}

This study was conducted according to the guidelines laid down in the Declaration of Helsinki and approved by the Human Use Review Committee at the US Army Research Institute of Environmental Medicine. The investigators have adhered to the policies for protection of human subjects as prescribed in DoD Instruction 3216.02, and the study was conducted in adherence to the provisions of 32 CFR Part 219. Human subjects participated in these studies after giving their free and informed voluntary consent.

The present study was conducted using a subset of volunteers enrolled in the previously published parent study, which examined the effects of $\mathrm{Ca} /$ vitamin $\mathrm{D}$ supplementation on bone health during $\mathrm{IMT}^{(4)}$. In brief, volunteer recruitment, enrolment and study completion occurred between February and April 2013 at Fort Sill, OK $\left(34 \cdot 7^{\circ} \mathrm{N}\right.$ latitude). Male and female subjects between the ages of 18 and 42 years who entered US Army basic combat training (BCT) during February 2013 were eligible to volunteer. Exclusion criteria included the following: $<18$ years of age, pregnant or lactating women, history of kidney disease or renal calculi or allergy to any component of the food product bars. A total of 152 volunteers (ninety-eight males and fifty-four females) with complete pre- and post-BCT panels for all analytes were included in this sub-analysis.

\section{Intervention}

Volunteers were block randomised by race and sex to one of the two intervention groups: a placebo bar or a Ca/vitamin D-fortified bar. Volunteers were then assigned a volunteer ID. Volunteers and all research personnel conducting data collection and/or analysis were blinded to the group assignment. Bars were specially manufactured by the Combat Feeding Directorate at the Natick Soldier Systems Center and labelled with a three-letter code to indicate the intervention group and the study key was maintained by the manufacturer. The nutrient composition of the bars is included in Table 1. Ca was added to the bars in the form of calcium carbonate and vitamin $\mathrm{D}$ was added as $\mathrm{D}_{3}$. Concentrations of $\mathrm{Ca}$ and vitamin $\mathrm{D}$ in the bars were selected based on previous reports demonstrating efficacy in reducing stress fracture incidence in military personnel ${ }^{(2)}$. The placebo and $\mathrm{Ca} /$ vitamin D bars were identical in taste and appearance and conformed to all ration standards for safety and stability.

The bars were individually labelled with volunteer ID numbers and packaged into 1-week allotments (fourteen bars each).
Table 1. Composition of placebo and calcium/vitamin $\mathrm{D}(\mathrm{Ca}+\mathrm{Vit} \mathrm{D})$ bars

\begin{tabular}{|c|c|c|}
\hline & Placebo & $\mathrm{Ca}+\mathrm{Vit} \mathrm{D}$ \\
\hline \multicolumn{3}{|l|}{ Macronutrients } \\
\hline Protein (g) & $1-2$ & $1-2$ \\
\hline Carbohydrate (g) & $23-25$ & $23-25$ \\
\hline Fat $(g)$ & 5 & 5 \\
\hline Energy (kJ) & $544-586$ & $544-586$ \\
\hline Energy (kcal) & $130-140$ & $130-140$ \\
\hline \multicolumn{3}{|l|}{ Micronutrients } \\
\hline $\mathrm{Ca}(\mathrm{mg})$ & $20^{*}$ & 1032†‡ \\
\hline Vit $D(\mu \mathrm{g})$ & $<0.02 \S$ & $13 \cdot 7 \ddagger \S$ \\
\hline $\mathrm{Fe}(\mathrm{mg})$ & $<2$ & $<2$ \\
\hline
\end{tabular}

Volunteers were provided the bars weekly and instructed to consume 2 bars/d: one during mid-morning and the other during mid-afternoon. Empty wrappers and uneaten bars were collected from each volunteer during the weekly bar exchanges in order to monitor compliance. Compliance was $88 \%$ in the placebo group and $81 \%$ in the $\mathrm{Ca} /$ vitamin $\mathrm{D}$ group.

\section{Basic combat training}

The BCT course consists of 9 weeks of physical and militaryspecific training. Physical training requirements include aerobic activities such as foot marching with weighted packs, obstacle courses, distance running and sprinting as well as muscle strength training and calisthenic exercises. Military training includes activities such as rappelling, weapons training, prolonged standing in formation and didactic classroom instruction. Estimates of physical activity levels during BCT at Fort Sill have been reported previously ${ }^{(18,19)}$. Soldiers consume 3 selfselected meals/d in a dining facility during BCT and are not permitted to consume dietary supplements.

\section{Anthropometrics}

All anthropometric measures were determined pre- and post$\mathrm{BCT}$, with the exception of height, which was measured pre-BCT to the nearest $0.1 \mathrm{~cm}$ using a stadiometer (Creative Health Products). Weight was determined to the nearest $0 \cdot 1 \mathrm{~kg}$ on a calibrated digital scale (Befour Scales; Befour, Inc.) and BMI was calculated as body weight $(\mathrm{kg}) /$ height $\left(\mathrm{m}^{2}\right)$. Skinfold thickness was measured at the tricep, suprailiac and abdomen for women and at the tricep, suscapula and chest for men. Measurements were made in duplicate to the nearest millimetre. If the measurements differed by $>2 \mathrm{~mm}$, a third measurement was taken. Body fat percentage was estimated using the three-site skinfold Jackson-Pollock equation ${ }^{(20-22)}$. Calculations were sex specific as previously reported ${ }^{(23,24)}$.

\section{Dietary intake}

Pre- and post-BCT dietary intakes were estimated using a selfadministered validated FFQ (Block 2005 FFQ; NutritionQuest) under the supervision of Registered Dietitians. The FFQ 
contained food lists developed from the National Health and Nutrition Examination Survey (NHANES) 1999-2002 dietary recall data. Nutrient intake data were excluded from the analysis if the energy intake was implausible $(<1255$ or $>18828 \mathrm{~kJ}$ ( $<300$ or $>4500 \mathrm{kcal})$ for females; $<3347$ or $>20920 \mathrm{~kJ}$ ( $<800$ or $>5000 \mathrm{kcal})$ for males).

\section{Blood collection and circulating biomarkers}

Fasting blood samples were collected by antecubital venepuncture into vacuum tubes (Vacutainer; Becton Dickinson). Serum and heparinised plasma were isolated, frozen and shipped to the Pennington Biomedical Research Center (PBRC) for assessment of indicators of Fe status. Serum ferritin and high-sensitivity C-reactive protein (CRP) levels were measured using an automated immunoassay instrument (Siemens Medical Solutions USA Inc.). Serum Fe and total Fe-binding capacity was measured using the Beckman Coulter DxC 600 Pro System (Beckman Coulter), and transferrin saturation was calculated by dividing the serum Fe by total Fe-binding capacity. Soluble transferrin receptor (sTfR) concentrations were measured using a commercially available immunoassay (Quantikine IVD; R\&D Systems Inc.). Intact PTH was measured by immunoassay (Siemens Immulite 2000; Siemens Medical Solutions USA Inc.). A small aliquot of whole, heparinised blood was used at the time the blood samples were obtained to determine iCa and $\mathrm{Hb}$ utilising a handheld iSTAT ${ }^{\circledR}$ System point-of-care device and Chem8+ Cartridges (Abbott Laboratories). PBRC follows good clinical practices and is accredited by the College of American Pathologists. All assays were run with standards and appropriate quality control material. In addition, PBRC runs external proficiency samples and results are compared with other laboratories across the country.

\section{Statistical analyses}

Data are reported as means and standard deviations. Normality was determined using the Kolmogorov-Smirnov test. Analyses were carried out using Student's $t$ test or two-factor repeatedmeasures ANOVA with time as the within-subjects factor and treatment group and sex as the between-subjects factors. When a significant interaction was observed, post hoc analyses with Bonferroni correction were carried out to identify those differences. Significance was demonstrated at $P<0 \cdot 05$. Data were analysed using SPSS version 21 (IBM Corp.) and graphed using GraphPad Prism 5.04 (GraphPad Software Inc.). Implausible serum ferritin values from one volunteer were not included in the final analysis; exclusion of these data did not affect study outcomes.

\section{Results}

A total of 152 volunteers with complete pre- and post-BCT panels for all Fe status indicators were included in this subanalysis: fifty males and twenty-five females in the placebo group and forty-eight males and twenty-nine females in the $\mathrm{Ca} /$ vitamin D group. Volunteer demographics pre- and post-BCT are included in Table 2 . No differences in sex, race or age were observed between treatment groups. Weight and BMI did not differ between groups or pre- and post-BCT. Similar to previous reports, body fat percentage decreased significantly during training $(P<0.05)^{(3,22)}$; however, no difference was observed between treatment groups.

Dietary intake of Ca and vitamin D did not differ between treatment groups; however, with the inclusion of the intervention bars, total Ca and vitamin D intake increased approximately 3- and 5-fold, respectively, in the $\mathrm{Ca} /$ vitamin $\mathrm{D}$ group from pre- to post-BCT $(P<0.05$; Table 3$)$. The level of dietary Fe consumed per day during BCT was above the RDA for males $(8 \mathrm{mg} / \mathrm{d})$ but below the RDA for females $(18 \mathrm{mg} / \mathrm{d}$; Table 3$)$. Separated by sex, males consumed 18.0 (SD 6.6) $\mathrm{mg} \mathrm{Fe} / \mathrm{d}$ and females consumed 14.3 (sD 5.6) $\mathrm{mg} \mathrm{Fe} / \mathrm{d}$. The level of energy and dietary protein, fat and $\mathrm{Zn}$ consumed per day decreased significantly $(P<0.05)$ during training.

Similar to the parent study, circulating concentrations of iCa and PTH did not differ at pre-BCT ${ }^{(4)}$; however, volunteers consuming the $\mathrm{Ca} /$ vitamin $\mathrm{D}$ snack bar had higher serum iCa $(P<0.05)$ and lower PTH $(P<0.05)$ at the completion of BCT compared with volunteers consuming the placebo snack bar (Fig. 1). Circulating 25(OH)D increased $(P<0.05)$ in both groups and $1,25(\mathrm{OH})_{2} \mathrm{D}$ did not change $(P>0.05)$ in either group during BCT (data not shown), as reported previously ${ }^{(4)}$. There were no sex differences in circulating $25(\mathrm{OH}) \mathrm{D}$ or $1,25(\mathrm{OH})_{2} \mathrm{D}$ in either treatment group (data not shown). Pooled data from males and females demonstrated that indices of $\mathrm{Fe}$ status were affected by BCT independent of the intervention (Fig. 2). Transferrin saturation, an indicator of early-stage Fe

Table 2. Volunteer demographics and body composition pre- and postbasic combat training $(\mathrm{BCT})^{\star}$

(Numbers and percentages; mean values and standard deviations)

\begin{tabular}{|c|c|c|c|c|c|}
\hline & \multicolumn{2}{|c|}{ Placebo ( $n 75)$} & \multicolumn{2}{|c|}{$\mathrm{Ca}+$ Vit $\mathrm{D}(n 77)$} & \multirow[b]{2}{*}{ Effect } \\
\hline & $n$ & $\%$ & $n$ & $\%$ & \\
\hline \multicolumn{6}{|l|}{ Sex } \\
\hline Male & 50 & 67 & 48 & 62 & \\
\hline Female & 25 & 33 & 29 & 38 & \\
\hline \multicolumn{6}{|l|}{ Race } \\
\hline White & 49 & 65 & 47 & 61 & \\
\hline Black & 18 & 24 & 19 & 25 & \\
\hline Asian & 3 & 4 & 2 & 2 & \\
\hline \multirow[t]{2}{*}{ Other } & 5 & 7 & 9 & 12 & \\
\hline & Mean & SD & Mean & SD & \\
\hline \multicolumn{6}{|c|}{ Age (years) } \\
\hline Pre & 21.4 & $3 \cdot 8$ & 21.2 & 3.7 & \\
\hline \multicolumn{6}{|c|}{ Weight (kg) } \\
\hline Pre & 73.4 & $13 \cdot 1$ & $70 \cdot 6$ & $12 \cdot 8$ & \\
\hline Post & $73 \cdot 1$ & 11.2 & $70 \cdot 1$ & $10 \cdot 4$ & \\
\hline \multicolumn{6}{|c|}{ Body fat (\%) } \\
\hline Pre & $16 \cdot 8$ & $8 \cdot 2$ & $17 \cdot 2$ & 8.4 & \\
\hline Post & $13 \cdot 3$ & $6 \cdot 6$ & $13 \cdot 4$ & $7 \cdot 0$ & $\mathrm{~T}$ \\
\hline \multicolumn{6}{|c|}{ BMI $\left(\mathrm{kg} / \mathrm{m}^{2}\right)$} \\
\hline Pre & 24.7 & 2.9 & $24 \cdot 2$ & $3 \cdot 3$ & \\
\hline Post & $24 \cdot 6$ & $2 \cdot 2$ & $24 \cdot 1$ & $2 \cdot 4$ & \\
\hline
\end{tabular}

$\mathrm{Ca}+$ Vit $\mathrm{D}, \mathrm{Ca} / \mathrm{vitamin} \mathrm{D} ; \mathrm{T}$, time.

* Analyses were computed using Student's $t$ test or repeated-measures ANOVA with time as the within-subjects factor and treatment group as the between-subjects factor. The Bonferroni correction was used for post hoc comparisons. No differences between treatment groups were observed. Time indicates significant difference between pre- and post-BCT $(P<0.05)$. 
Table 3. Dietary intake pre- and post-basic combat training (BCT) †‡ (Mean values and standard deviations)

\begin{tabular}{|c|c|c|c|c|c|c|}
\hline & \multicolumn{2}{|c|}{ Placebo ( $n$ 69) } & \multicolumn{2}{|c|}{$\mathrm{Ca}+$ Vit $\mathrm{D}(n$ 64) } & \multirow[b]{2}{*}{ Effect } & \multirow[b]{2}{*}{ RDA§ } \\
\hline & Mean & SD & Mean & SD & & \\
\hline \multicolumn{7}{|c|}{ Macronutrients } \\
\hline \multicolumn{7}{|c|}{ Protein $(g / d)$} \\
\hline Pre & $87 \cdot 8$ & $40 \cdot 3$ & $90 \cdot 7$ & 45.4 & \multirow[b]{2}{*}{$\mathrm{T}$} & - \\
\hline Post & 73.0 & 29.4 & $76 \cdot 4$ & $25 \cdot 0$ & & \\
\hline \multicolumn{7}{|c|}{ Carbohydrate $(\mathrm{g} / \mathrm{d})$} \\
\hline Pre & 274 & 114 & 270 & 112 & & \multirow[t]{2}{*}{-} \\
\hline Post & 248 & 94 & 276 & 98 & & \\
\hline \multicolumn{7}{|l|}{ Fat $(g / d)$} \\
\hline Pre & 89.4 & $42 \cdot 2$ & $96 \cdot 3$ & 43.9 & \multirow[b]{2}{*}{$\mathrm{T}$} & - \\
\hline Post & $71 \cdot 7$ & $28 \cdot 3$ & $75 \cdot 3$ & $28 \cdot 1$ & & \\
\hline \multicolumn{7}{|c|}{ Energy (kJ/d) } \\
\hline Pre & 9443 & 3966 & 9740 & 4088 & \multirow[b]{2}{*}{$\mathrm{T}$} & \multirow[t]{2}{*}{-} \\
\hline Post & 7916 & 2908 & 8560 & 2833 & & \\
\hline \multicolumn{7}{|c|}{ Energy (kcal/d) } \\
\hline Pre & 2257 & 948 & 2328 & 977 & \multirow{3}{*}{ T } & - \\
\hline Post & 1892 & 695 & 2046 & 677 & & \\
\hline \multicolumn{6}{|c|}{ Micronutrients } & \\
\hline \multicolumn{7}{|c|}{$\mathrm{Ca}(\mathrm{mg} / \mathrm{d})$} \\
\hline Pre & 994 & 483 & 981 & 486 & & Male: 1000 \\
\hline Post & 943 & 508 & 1028 & 371 & & Female: 1000 \\
\hline \multicolumn{7}{|c|}{$\mathrm{Fe}(\mathrm{mg} / \mathrm{d})$} \\
\hline Pre & $15 \cdot 7$ & $7 \cdot 1$ & $16 \cdot 2$ & $7 \cdot 7$ & & Male: 8 \\
\hline Post & $16 \cdot 1$ & $6 \cdot 3$ & $17 \cdot 2$ & $6 \cdot 6$ & & Female: 18 \\
\hline \multicolumn{7}{|c|}{$\mathrm{Zn}(\mathrm{mg} / \mathrm{d})$} \\
\hline Pre & 13.3 & $6 \cdot 3$ & 14.5 & 9.2 & & Male: 11 \\
\hline Post & 10.2 & 4.6 & 11.2 & $4 . \overline{2}$ & $\mathrm{~T}$ & Female: 8 \\
\hline \multicolumn{7}{|c|}{ Vit D $(\mu \mathrm{g} / \mathrm{d})$} \\
\hline Pre & 4.48 & 3.15 & 4.63 & $4 \cdot 30$ & & Male: 15 \\
\hline Post & $5 \cdot 25$ & 3.45 & 5.50 & 2.85 & $\mathrm{~T}$ & Female: 15 \\
\hline \multicolumn{7}{|c|}{ Including bars } \\
\hline \multicolumn{7}{|c|}{ Total energy $(\mathrm{kJ} / \mathrm{d})$} \\
\hline Post & 8941 & 2925 & 9447 & 2837 & & - \\
\hline \multicolumn{7}{|c|}{ Total energy $(\mathrm{kcal} / \mathrm{d})$} \\
\hline Post & 2137 & 699 & 2258 & 678 & & - \\
\hline \multicolumn{7}{|c|}{ Total Ca (mg/d) } \\
\hline Post & 980 & 508 & $2710^{\star}$ & 475 & $T \times G$ & - \\
\hline \multicolumn{7}{|c|}{$\operatorname{Vit} D(\mu \mathrm{g} / \mathrm{d})$} \\
\hline Post & 5.25 & 3.45 & $27 \cdot 8^{\star}$ & 5.13 & $T \times G$ & _- \\
\hline
\end{tabular}

$\mathrm{Ca}+$ Vit D, Ca/vitamin D; T, time; G, group.

* Significantly different between pre- and post-BCT $(P<0.05)$.

† Data were analysed using repeated-measures ANOVA with time as the within-subjects factor and treatment group as the between-subjects factor.

Significant effects of time and treatment group are shown $(P<0.05)$. Post hoc Bonferroni correction was used for time-by-group comparisons.

‡ Nutrient intake data were excluded from the analysis if energy intake was implausible ( $<1255$ or $>18828 \mathrm{~kJ}(<300$ or $>4500 \mathrm{kcal})$ for females; $<3347$ or $>20920 \mathrm{~kJ}$ ( $<800$ or $>5000 \mathrm{kcal})$ for males $)$.

$\S$ RDA for 19-30-year-old males and females.
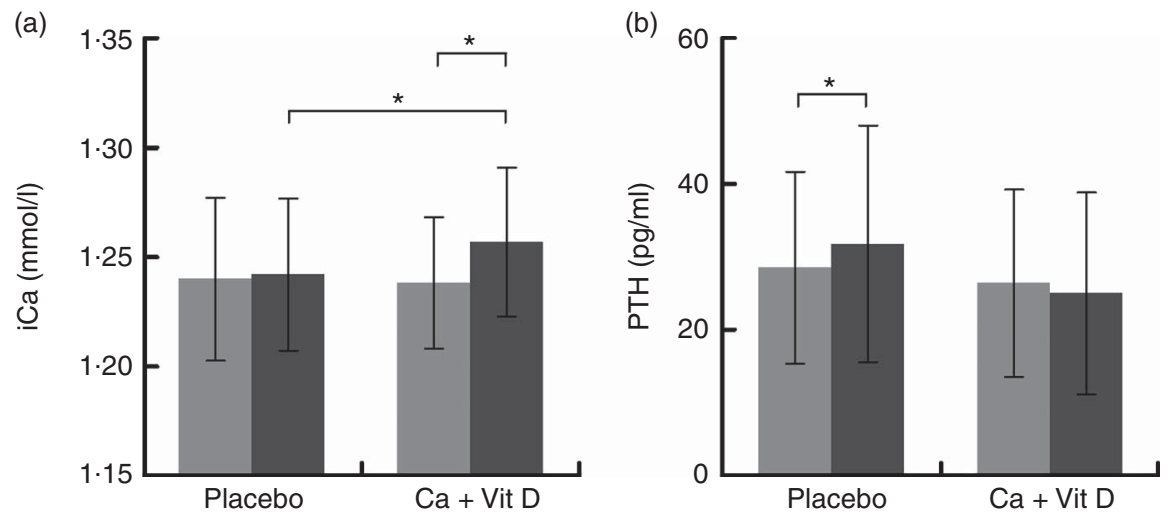

Fig. 1. Indicators of calcium status pre- and post-basic combat training $(B C T)$ in male and female soldiers receiving placebo or calcium/vitamin $D(C a+V i t ~ D)$ bars. (a) lonised calcium (iCa) and (b) parathyroid hormone (PTH). Values are means and standard deviations, and two-factor repeated-measures ANOVA with Bonferroni correction was utilised for comparisons represented by vertical bars. * Significantly different: $P<0.05$. Placebo: $n 75$; Ca + Vit D: $n$ 77. $\square$, Pre-BCT; $\square$, post-BCT. 
(a)

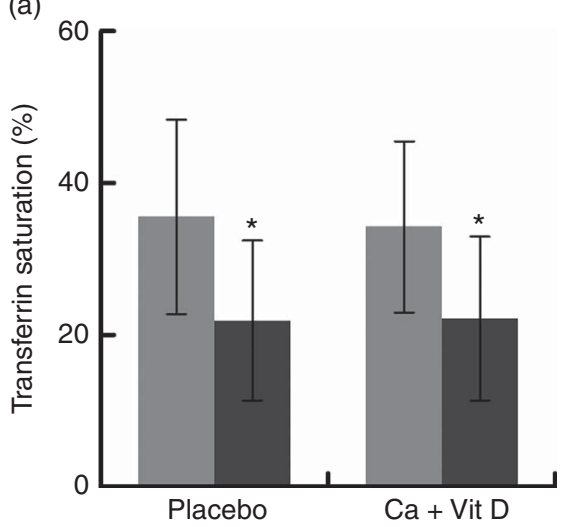

(c)

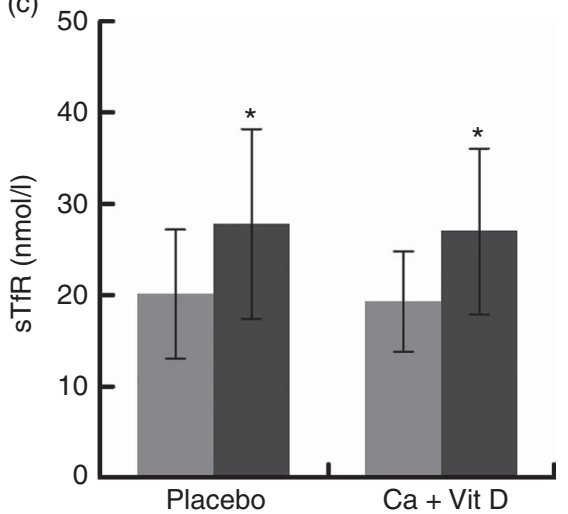

(b)

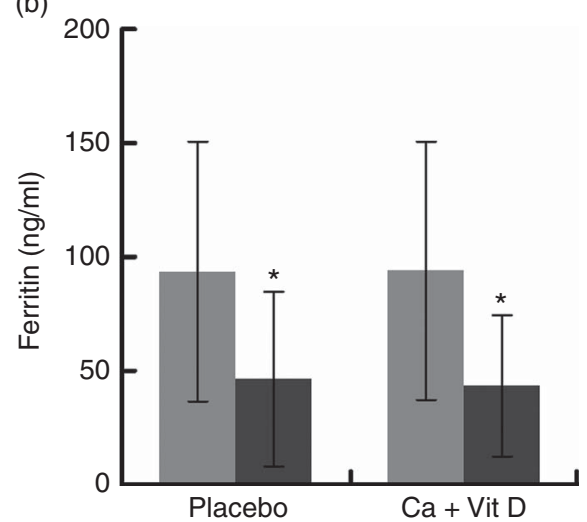

(d)

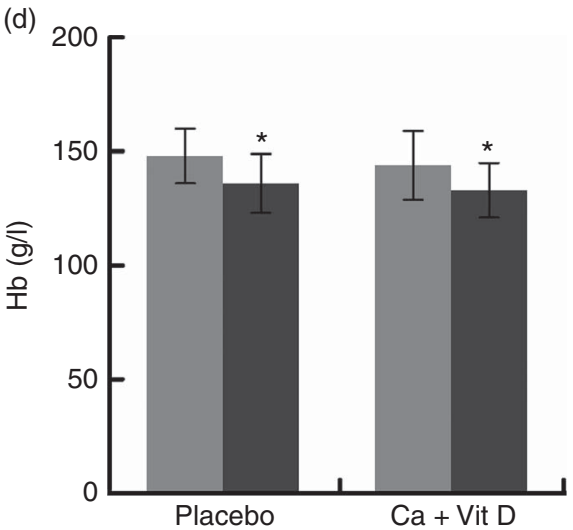

Fig. 2. Iron status indicators pre- and post-basic combat training (BCT) in male and female soldiers receiving placebo or calcium/vitamin $D(C a+V i t ~ D)$ bars. (a) Transferrin saturation, (b) serum ferritin, (c) soluble transferrin receptor (sTfR) and (d) Hb. Values are means and standard deviations, and were analysed using two-factor repeated-measures ANOVA with time as the within-subjects factor and treatment group as the between-subjects factor. The Bonferroni correction was used for post hoc comparisons. No differences between treatments were observed. * Significantly different between pre- and post-BCT $(P<0.05)$. Placebo: $n 74-75$; $\mathrm{Ca}+$ Vit D: $n$ 77. $\square$, Pre-BCT; $\square$, post-BCT.

depletion, was reduced $>35 \%(P<0.05$; Fig. 2(a)) at the completion of the BCT; however, no differences were observed between placebo and $\mathrm{Ca} /$ vitamin $\mathrm{D}$ groups. Serum ferritin decreased by approximately $50 \%(P<0 \cdot 05$; Fig. $2(\mathrm{~b}))$ and sTfR increased by approximately $28 \%(P<0.05$; Fig. $2(\mathrm{c}))$ post-BCT compared with pre-BCT, reflecting reduced Fe stores and tissue Fe deficiency, respectively, although no differences were observed between treatment groups. Hb levels decreased by approximately $8 \%(P<0.05$; Fig. $2(d))$ at the completion of BCT, although no differences in $\mathrm{Hb}$ levels were observed between placebo and $\mathrm{Ca} /$ vitamin $\mathrm{D}$ groups. When separated by sex, Fe status declined in both male and female volunteers at the completion of BCT independent of the intervention (Table 4). However, Ca/vitamin D supplementation preserved transferrin saturation and $\mathrm{Hb}$ concentrations in female volunteers in the intervention group compared with the placebo group. Similar to a recent report ${ }^{(8)}$, the magnitude of change of Fe status indicators from pre- to post-BCT was greater in female volunteers compared with male volunteers. This was reflected in a larger decrease in transferrin saturation (male: $37 \cdot 0$ (sD 24.4) \%, female: 20.7 (sD 69.6) \%; $P<0.05$ ) and serum ferritin (male: $52 \cdot 0$ (sD 20.1) \%, female: 44.5 (sD 34.7) \%; $P=0.095$ ) and an increase in sTfR (male: 35.4 (SD 21.5) \%, female: 47.9 (SD 27.6) \%; $P<0.05)$. CRP increased $(P<0.05)$ throughout training but did not differ between groups (placebo: pre 2.69 (sD 6.22$) \mathrm{mg} / \mathrm{l}$, post $7.43(\mathrm{sD} 21.5) \mathrm{mg} / \mathrm{l} ; \mathrm{Ca} /$ vitamin D: pre 3.73 (sD 14.5) $\mathrm{mg} / \mathrm{l}$, post $6 \cdot 65(\mathrm{sD} 10 \cdot 0) \mathrm{mg} / \mathrm{l})$.

\section{Discussion}

The objective of this randomised, double-blind, placebocontrolled trial was to determine whether providing $2000 \mathrm{mg} / \mathrm{d}$ $\mathrm{Ca}$ in a fortified food product during 9 weeks of military training would negatively affect $\mathrm{Fe}$ status in young adults. These data indicate that consumption of a Ca/vitamin D-fortified snack does not further exacerbate the decline in Fe status that occurred in both male and female soldiers. These data coupled with the results from the parent study ${ }^{(4)}$ indicate that $\mathrm{Ca} /$ vitamin $\mathrm{D}$ supplementation provides benefits to bone health without negatively affecting Fe status.

The timing and duration of $\mathrm{Ca}$ /vitamin $\mathrm{D}$ supplementation relative to $\mathrm{Fe}$ intake may explain why supplementation did not impact $\mathrm{Fe}$ absorption/status. In the present study, the $\mathrm{Ca} /$ vitamin $\mathrm{D}$ bar was provided twice daily between meals rather than at meal time. Most studies in humans that have demonstrated a reduction in Fe absorption with supplemental $\mathrm{Ca}$ have been single meal studies using the dual radioisotope method. For example, Hallberg et al. ${ }^{(14)}$ reported a dose-dependent decrease 
Table 4. Indices of iron status in male and female soldiers pre- and post-basic combat training (BCT) $\dagger$

(Mean values and standard deviations)

\begin{tabular}{|c|c|c|c|c|c|}
\hline & \multicolumn{2}{|c|}{$\begin{array}{c}\text { Placebo } \\
(n \text { 74-75)‡ }\end{array}$} & \multicolumn{2}{|c|}{$\begin{array}{c}\mathrm{Ca}+\mathrm{Vit} \mathrm{D} \\
(n 77) \S\end{array}$} & \multirow[b]{2}{*}{ Effect } \\
\hline & Mean & SD & Mean & SD & \\
\hline \multicolumn{6}{|c|}{ Transferrin saturation (\%) } \\
\hline \multicolumn{6}{|l|}{ Male } \\
\hline Pre & 38.8 & $11 \cdot 2$ & 39.5 & 8.4 & \\
\hline Post & $24 \cdot 6^{\star}$ & $10 \cdot 1$ & $23 \cdot 4^{\star}$ & 8.4 & \\
\hline \multicolumn{6}{|l|}{ Female } \\
\hline Pre & $29 \cdot 0$ & $13 \cdot 6$ & $25 \cdot 5$ & $10 \cdot 2$ & \\
\hline Post & $16 \cdot 4^{\star}$ & $9 \cdot 4$ & $20 \cdot 0$ & $13 \cdot 8$ & $\mathrm{~T} \times \mathrm{S} \times \mathrm{G}$ \\
\hline \multicolumn{6}{|c|}{ Serum ferritin (ng/ml) } \\
\hline \multicolumn{6}{|l|}{ Male } \\
\hline Pre & 112 & $56 \cdot 5$ & 118 & $49 \cdot 3$ & \\
\hline Post & $57 \cdot 3^{*}$ & $40 \cdot 7$ & $53 \cdot 6^{*}$ & $32 \cdot 0$ & \\
\hline \multicolumn{6}{|l|}{ Female } \\
\hline Pre & $57 \cdot 4$ & 38.4 & 54.5 & $45 \cdot 4$ & \\
\hline Post & $25 \cdot 6^{*}$ & 21.9 & $26 \cdot 6^{\star}$ & $20 \cdot 5$ & $T \times S$ \\
\hline \multicolumn{6}{|c|}{$\operatorname{sTfR}(\mathrm{nmol} / \mathrm{l})$} \\
\hline \multicolumn{6}{|l|}{ Male } \\
\hline Pre & $19 \cdot 3$ & 3.6 & $19 \cdot 3$ & 4.2 & \\
\hline Post & $25 \cdot 8^{*}$ & $6 \cdot 0$ & $26 \cdot 0^{*}$ & $5 \cdot 6$ & \\
\hline \multicolumn{6}{|l|}{ Female } \\
\hline Pre & $21 \cdot 7$ & $11 \cdot 3$ & $19 \cdot 3$ & $7 \cdot 2$ & \\
\hline Post & $31.6^{*}$ & $15 \cdot 4$ & $28 \cdot 7^{\star}$ & $12 \cdot 9$ & $T \times S$ \\
\hline \multicolumn{6}{|l|}{$\mathrm{Hb}(\mathrm{g} / \mathrm{l})$} \\
\hline \multicolumn{6}{|l|}{ Male } \\
\hline Pre & 154 & 8.0 & 154 & $9 \cdot 0$ & \\
\hline Post & $141^{*}$ & 10 & $137^{*}$ & 11 & \\
\hline \multicolumn{6}{|l|}{ Female } \\
\hline Pre & 135 & $9 \cdot 0$ & 129 & $9 \cdot 0$ & \\
\hline Post & $124^{*}$ & 11 & 127 & 9.0 & $\mathrm{~T} \times \mathrm{S} \times \mathrm{G}$ \\
\hline
\end{tabular}

$\mathrm{Ca}+$ Vit D, Ca/vitamin D; T, time; S, sex; G, group; sTfR, soluble transferrin receptor ${ }^{*}$ Significantly different between pre- and post-BCT $(P<0.05)$.

$\dagger$ Data were analysed using two-factor repeated-measures ANOVA with time as the within-subjects factor and sex and treatment group as the between-subjects factors. Post hoc Bonferroni correction was used to identify interaction differences.

No differences between treatment groups were observed.

‡ Placebo: male, $n$ 49-50; female, $n 25$.

$\S \mathrm{Ca}+$ Vit D: male, $n$ 8; female, $n 29$.

of $50-60 \%$ in Fe absorption in men and women given 40-600 mg $\mathrm{Ca}$ added to a test meal. Similarly, in a three-period cross-over study, premenopausal women consuming a $500 \mathrm{mg}$ Ca supplement absorbed approximately $55 \%$ less Fe compared with the placebo ${ }^{(12)}$. Thus, Ca given separate from meals may limit interference from inhibitors such as phytate or may limit the direct effects of $\mathrm{Ca}$ on $\mathrm{Fe}$ transport ${ }^{(17)}$.

Longitudinal studies examining the effects of Ca over time have found a reduced effect or no effect of $\mathrm{Ca}$ on Fe absorption compared with single meal studies ${ }^{(15,16)}$ and no effect of $\mathrm{Ca}$ on the Fe status of men or women ${ }^{(17,25,26)}$. This suggests that absorptive mechanisms may have adapted in the presence of high $\mathrm{Ca}$ intakes to maintain $\mathrm{Fe}$ homoeostasis over the longer study period. Mechanistically, $\mathrm{Ca}$ is thought to transiently inhibit Fe transport in the small intestine by interacting with divalent metal transporter 1 (DMT1) and/or ferroportin, thereby reducing $\mathrm{Fe}$ assimilation. However, over time, adaptive mechanisms may restore Fe absorption. Shawki \& Mackenzie ${ }^{(27)}$ reported that $\mathrm{Ca}$ is not transported by DMT1, but that Ca blocks DMT1-mediated Fe uptake $\left({ }^{55} \mathrm{Fe}\right)$ in Xenopus oocytes. Using differentiated Caco-2 cells grown on Transwell inserts,
Lönnerdal ${ }^{(28)}$ demonstrated a significant reduction in basolateral transfer of Fe when the apical chamber was incubated with medium containing $1 \mu \mathrm{M}$-iron sulphate labelled with ${ }^{59} \mathrm{Fe}$ and $100 \mu \mathrm{m}$-calcium chloride compared with cells with no calcium chloride. Interestingly, a greater reduction in Fe transport was observed at $1.5 \mathrm{~h}$ compared with $4 \mathrm{~h}^{(28)}$. Moreover, DMT1 expression was slightly reduced and surface-bound Ferroportin was significantly decreased at $1.5 \mathrm{~h}$, whereas expression of both transporters increased at $4 \mathrm{~h}^{(28)}$. Using a similar model, it has been reported that DMT1 becomes internalised with high Ca concentrations ${ }^{(29)}$. Collectively, these results suggest that Ca likely inhibits Fe transport by signalling for the internationalisation of DMT1 and/or ferroportin; however, adaptive mechanisms may preserve $\mathrm{Fe}$ status in the event that $\mathrm{Ca}$ and $\mathrm{Fe}$ are consumed together for longer periods of time.

Fe status should also be considered when examining the effects of added $\mathrm{Ca}$ on Fe absorption. Previous studies have reported no effects on functional Fe or Fe stores in Fe-depleted individuals when given supplemental $\mathrm{Ca}^{(17)}$. This is likely due to heightened absorptive mechanisms for Fe when status is low ${ }^{(30,31)}$. In the present study, decrements in $\mathrm{Fe}$ status indicators occurred in male and female soldiers, regardless of treatment group; however, the Fe status of female soldiers was reduced compared with that of male soldiers. This is in agreement with recent reports noting a sharper decline in Fe status in female soldiers compared with male soldiers during $\mathrm{BCT}^{(8)}$. Dietary $\mathrm{Fe}$ intake in both the present study and previous studies $^{(8)}$ was $>200 \%$ and approximately $90 \%$ of the RDA for men and women, respectively (Table 3 ). Thus, women may be more susceptible to poor Fe status during BCT due to dietary intakes below the RDA. Further, women may experience increased $\mathrm{Fe}$ losses through menstruation ${ }^{(32)}$. The relatively reduced Fe status of female soldiers compared with male soldiers and potential adaptive mechanisms to increase Fe absorption in response to sustained $\mathrm{Ca}$ intakes could be one possible explanation for the observed preservation in transferrin saturation and $\mathrm{Hb}$ in female soldiers consuming the $\mathrm{Ca}$ /vitamin $\mathrm{D}$ snack bars.

Military trainees encounter many obstacles including musculoskeletal injury that may affect the successful completion of BCT. Nutrition is one factor that can be modified to mitigate the risk of injury while optimising physical and cognitive performance. Countermeasures to combat stress fracture are important for maintaining the health of military trainees and increasing the likelihood of successful completion of training, especially for female military personnel. This is the first study to examine the effects of $\mathrm{Ca} /$ vitamin $\mathrm{D}$ supplementation on measures of Fe status in the military population. Strengths of this study include the repeated-measures design, sample size, multiple measures of Fe status, dietary intake data and the lack of dietary supplements during BCT. A limitation of the study was the inability to measure apparent $\mathrm{Fe}$ absorption during BCT. Data from the present study and the parent study ${ }^{(4)}$ indicate that $\mathrm{Ca} /$ vitamin $\mathrm{D}$ supplementation provided as a snack through the use of a fortified food product provides benefits to bone health without negatively affecting Fe status. Future studies should determine an effective means to protect bone health throughout BCT while preserving or improving Fe status. 


\section{Acknowledgements}

The authors acknowledge the study volunteers and the study research team.

Approved for public release; distribution is unlimited. The opinions or assertions contained here are the private views of the authors and are not to be construed as official or as reflecting the views of the army or the Department of Defense. Any citations or commercial organisations and trade names in this report do not constitute an Official Department of the Army endorsement of approval of the products or services of these organisations.

Supported in part by the US Army Medical Research and Materiel Command and appointment to the US Army Research Institute of Environmental Medicine administered by the Oak Ridge Institute for Science and Education (to S. R. H.) through an interagency agreement between the US Department of Energy and the US Army Medical Research and Materiel Command.

E. G.-S., A. J. Y. and J. P. M. designed the study; E. G.-S., L. J. L., S. J. C., S. M. P. and J. P. M. executed the study; S. R. H., E. G.-S., L. J. L. and J. P. M. analysed the data and wrote the manuscript. J. P. M. had primary responsibility for the final content, and all the authors read and approved the final version of the manuscript.

None of the authors has any conflicts of interest to report.

\section{References}

1. Jones BH, Thacker SB, Gilchrist J, et al. (2002) Prevention of lower extremity stress fractures in athletes and soldiers: a systematic review. Epidemiol Rev 24, 228-247.

2. Lappe J, Cullen D, Haynatzki G, et al. (2008) Calcium and vitamin D supplementation decreases incidence of stress fractures in female navy recruits. J Bone Miner Res 23, 741-749.

3. Lutz LJ, Karl JP, Rood JC, et al. (2012) Vitamin D status, dietary intake, and bone turnover in female soldiers during military training: a longitudinal study. J Int Soc Sports Nutr 9, 38.

4. Gaffney-Stomberg E, Lutz LJ, Rood JC, et al. (2014) Calcium and vitamin D supplementation maintains parathyroid hormone and improves bone density during initial military training: a randomized, double-blind, placebo controlled trial. Bone 68, 46-56.

5. McClung JP, Marchitelli LJ, Friedl KE, et al. (2006) Prevalence of iron deficiency and iron deficiency anemia among three populations of female military personnel in the US Army. J Am Coll Nutr 25, 64-69.

6. McClung JP, Karl JP, Cable SJ, et al. (2009) Randomized, double-blind, placebo-controlled trial of iron supplementation in female soldiers during military training: effects on iron status, physical performance, and mood. Am J Clin Nutr $\mathbf{9 0}$, $124-131$.

7. McClung JP, Karl JP, Cable SJ, et al. (2009) Longitudinal decrements in iron status during military training in female soldiers. Br J Nutr 102, 605-609.

8. Yanovich R, Karl JP, Yanovich E, et al. (2015) Effects of basic combat training on iron status in male and female soldiers: a comparative study. US Army Med Dep J Apr-Jun, 57-63.

9. Kletzien SW (1940) Iron metabolism. I. The role of calcium in iron assimilation. J Nutr 19, 187-197.

10. Barton JC, Conrad ME \& Parmley RT (1983) Calcium inhibition of inorganic iron absorption in rats. Gastroenterology $\mathbf{8 4}$, 90-101.
11. Monsen ER \& Cook JD (1976) Food iron absorption in human subjects. IV. The effects of calcium and phosphate salts on the absorption of nonheme iron. Am J Clin Nutr 29, 1142-1148.

12. Dawson-Hughes B, Seligson FH \& Hughes VA (1986) Effects of calcium carbonate and hydroxyapatite on zinc and iron retention in postmenopausal women. Am J Clin Nutr 44, 83-88.

13. Deehr MS, Dallal GE, Smith KT, et al. (1990) Effects of different calcium sources on iron absorption in postmenopausal women. Am J Clin Nutr 51, 95-99.

14. Hallberg L, Brune M, Erlandsson M, et al. (1991) Calcium: effect of different amounts on nonheme- and heme-iron absorption in humans. Am J Clin Nutr 53, 112-119.

15. Gleerup A, Rossander-Hulten L \& Hallberg L (1993) Duration of the inhibitory effect of calcium on non-haem iron absorption in man. Eur J Clin Nutr 47, 875-879.

16. Reddy MB \& Cook JD (1997) Effect of calcium intake on nonheme-iron absorption from a complete diet. Am J Clin Nutr 65, 1820-1825.

17. Ilich-Ernst JZ, McKenna AA, Badenhop NE, et al. (1998) Iron status, menarche, and calcium supplementation in adolescent girls. Am J Clin Nutr 68, 880-887.

18. Knapik JJ, Sharp MA, Darakjy S, et al. (2006) Temporal changes in the physical fitness of US Army recruits. Sports Med 36, 613-634.

19. Simpson K, Redmond JE, Cohen BS, et al. (2013) Quantification of physical activity performed during US Army basic combat training. . US Army Med Dep J Oct-Dec, 55-65.

20. Nindl BC, McClung JP, Miller JK, et al. (2011) Bioavailable IGF-I is associated with fat-free mass gains after physical training in women. Med Sci Sports Exerc 43, 793-799.

21. Margolis LM, Pasiakos SM, Karl JP, et al. (2012) Differential effects of military training on fat-free mass and plasma amino acid adaptations in men and women. Nutrients $\mathbf{4}, 2035-2046$.

22. Pasiakos SM, Karl JP, Lutz LJ, et al. (2012) Cardiometabolic risk in US Army recruits and the effects of basic combat training. PLOS ONE 7, e31222.

23. Jackson AS \& Pollock ML (1978) Generalized equations for predicting body density of men. Br J Nutr $\mathbf{4 0}, 497-504$.

24. Jackson AS, Pollock ML \& Ward A (1980) Generalized equations for predicting body density of women. Med Sci Sports Exerc 12, 175-181.

25. Kalkwarf HJ \& Harrast SD (1998) Effects of calcium supplementation and lactation on iron status. Am J Clin Nutr 67, 1244-1249.

26. Minihane AM \& Fairweather-Tait SJ (1998) Effect of calcium supplementation on daily nonheme-iron absorption and longterm iron status. Am J Clin Nutr 68, 96-102.

27. Shawki A \& Mackenzie B (2010) Interaction of calcium with the human divalent metal-ion transporter-1. Biochem Biophys Res Commun 393, 471-475.

28. Lönnerdal B (2010) Calcium and iron absorption - mechanisms and public health relevance. Int J Vitam Nutr Res 80, 293-299.

29. Thompson BA, Sharp PA, Elliott R, et al. (2010) Inhibitory effect of calcium on non-heme iron absorption may be related to translocation of DMT-1 at the apical membrane of enterocytes. J Agric Food Chem 58, 8414-8417.

30. Bezwoda WR, Bothwell TH, Torrance JD, et al. (1979) The relationship between marrow iron stores, plasma ferritin concentrations and iron absorption. Scand J Haematol 22, 113-120.

31. Taylor P, Martinez-Torres C, Leets I, et al. (1988) Relationships among iron absorption, percent saturation of plasma transferrin and serum ferritin concentration in humans. J Nutr $\mathbf{1 1 8}$, $1110-1115$

32. Hallberg L \& Rossander-Hulten L (1991) Iron requirements in menstruating women. Am J Clin Nutr 54, 1047-1058. 